\title{
ARTICLE
}

\section{Are Engineering and Social Justice (In)commensurable? A Theoretical Exploration of Macro-Sociological Frameworks}

\author{
Jon A. Leydens, ${ }^{*}$ Juan C. Lucena, ${ }^{\dagger}$ and Jen Schneider ${ }^{\ddagger}$ \\ Division of Liberal Arts and International Studies, Colorado School of Mines \\ * jleydens@mines.edu, † jlucena@mines.edu, ¥ jen.schneider@mines.edu
}

\begin{abstract}
The degree to which engineering and social justice as fields of practice are (in)commensurable remains an open question. To illuminate important dimensions of that question, we explore intersections between those fields and two macro-sociological frameworks. Those theoretical frameworks-structural functionalism and social conflict-represent contrasting perspectives on how society should be organized. Specifically, we reveal conceptual alignments between structural functionalism and engineering/engineering education and between social conflict and social justice. Those alignments suggest some salient potential catalysts for tensions between engineering and social justice and provide a useful ideological mirror for reflection by all who are committed to the engineering profession and/or to social justice.
\end{abstract}

KEYWORDS: social justice, engineering, theory, structural functionalism, social conflict

\section{INTRODUCTION}

Multiple tensions exist at the intersection between engineering and social justice (SI) as fields of practice. To understand these tensions, we need to first define what we mean by both engineering and SJ, as well as provide examples of such tensions. In this paper, we posit that these tensions result in communication gaps exacerbated by underlying and diverse theoretical frameworks. We explore two sociological frameworks to better understand the degree to which engineering and social justice are incommensurable or commensurable as fields of practice.

First, we define engineering as the set of educational and professional practices aimed at developing, implementing and/or improving technologies for a specific purpose. ${ }^{1}$ Second, broadly speaking, we see SJ as referring to practices aimed at a more equitable distribution of societal advantages and disadvantages, or what have more traditionally been called rewards (or opportunities) and burdens (or harms) (Capeheart \& Milovanovic, 2007). To illustrate the nature of tensions between these definitions of engineering and SJ, we describe the motives for our inquiry, the first related to events at a 2008 workshop at the U.S. National Academy of Engineering (NAE) and the second related to texts that have been influential in engineering education, particularly in the U.S. context. However, the bulk of the paper is devoted to a theoretical examination of the two sociological frameworks-the structural-functionalist and social-conflict frameworks-which we

\footnotetext{
1 Depending on the cultural and institutional contexts, engineering could have a stronger emphasis on science, design, manual labor, management or public service. We are well aware of these differences yet want to provide here a basic definition that works well in most cultural contexts.
} 
find to have significant potential in helping illuminate potential origins of conflicts between engineering and social justice.

\section{BACKGROUND: MOTIVES FOR INQUIRY}

Our interest in exploring theoretical frameworks emerged from the desire to understand the catalysts behind tensions between engineering and SJ and the reasons for the lack of explicit connections between engineering and SJ. Since our awareness of those tensions and missing connections emerged from a 2008 workshop and from a brief review of engineering literature, respectively, we discuss below these motives for our theoretical inquiry.

In October 2008, the three authors, along with several engineering educators and engineers in prominent engineering organizations, were invited to a U.S. National Science Foundation (NSF)sponsored workshop on Social Justice, Sustainable Community Development, and Engineering, hosted by the NAE in Washington, DC. At that event, a clear tension emerged between engineering and SJ. Although NSF had funded the workshop and NAE had endorsed the workshop, title, and lineup of speakers, some influential engineers in attendance strongly resisted proposals for the profession to meaningfully address SJ theories and practices. These engineers occupied key roles in prominent engineering organizations, such as the U.S. Army Corps of Engineers and the National Society of Professional Engineers. Some of the resistance was rooted in their notions of societal organization and in the socio-historical associations linking social justice with political progressivism (e.g., socialism, Marxism, or social democracy). Those engineers also expressed discomfort at the idea of engaging in activities that might have such an overtly "political" stance. However, they expressed no reservation about taking an equally political stance in supporting the engineering status quo, which is also imbued with political values that are less socially controversial-and thus less visible.

Hence, a communicative divide developed during the workshop, and was most pronounced between workshop participants interested in seeing SJ placed more centrally and explicitly within engineering education and the engineering profession, and those resistant to such placement. That rift was manifested by workshop participants' use of potentially reductive labels such as "neoliberal" and "socialist." Also, during the workshop, breakout groups reconvened to report on their findings, and when one such group indicated it had originally considered calling its collaborative document a "manifesto" but later opted for "declaration," a prominent engineer indicated that even considering the term manifesto confirmed his suspicions that SJ was inspired by socialist or communist ideals. To relieve-and satirize-some of the building tension, one engineer wondered aloud whether her red sweater would mark her as a communist. The intensity of that tension was largely subdued in the NAE's official workshop summary publication (Hollander \& National Academy of Engineering; National Academies Press, 2010). However, in a later comment on the workshop, Rachelle Hollander, NAE's Center for Engineering, Ethics, and Society Director and the workshop coordinator, remarked that at this workshop "the question of engineering and social justice was a hotly contested topic" (Hollander, 2010).

Despite these tensions, complete polarization did not occur. During the NAE workshop, an important phenomenon occurred: at the same time those engineers advocating for the status quo objected to the idea of explicitly linking SJ to the engineering profession, they were also keenly intrigued by the profession-enhancing potential of SJ initiatives. At the workshop, we heard inspiring accounts from engineers who were using their engineering knowledge in the service of SJ; even those resisting explicit links between SJ and engineering saw in such accounts clear long- 
range potential benefits, such as bolstering the recruitment of women and minorities and improving engineering's public image.

This aversion-cum-attraction to SJ has a rough corollary in the second catalyst for our inquiry, published literature on engineering education. In that literature, we observed missing connections in publications that have been particularly influential in U.S. engineering education. For instance, The Engineer of 2020, published by the NAE, is considered by many to be a forward-thinking vision for the engineering profession, and it calls to the fore societal issues that engineers will need to face, such as demographic diversity, population growth, and health care disparities (National Academy of Engineering, 2004). Each of these issues involves significant SJ dimensions which, as engineer and social-justice advocate Donna Riley has noted, include "the struggle to end different kinds of oppression, to create economic equality, to uphold human rights or dignity, and to restore right relationships among all people and the environment" (Riley, 2008, p. 4). Put another way, many SJ issues also potentially involve engineers and engineering, and many engineering issues also clearly involve SJ dimensions. However, despite such intersections, The Engineer of 2020 never explicitly looks at how engineers or the profession might address such dimensions of SJ. The closest it comes to calling for engineers to address SJ is in noting an aspiration "to a future where engineers are prepared to adapt to changes in global forces and trends and to ethically assist the world in creating a balance in the standard of living in developed and developing countries alike" (NAE, 2004 , p. 51). The act of acknowledging issues related to SJ and the simultaneous reluctance to call explicitly for engineering to address SJ is evident in other influential reports, such as the NAE's Grand Challenges ${ }^{2}$ and a policy statement by the American Society of Civil Engineers' Committee on Academic Prerequisites for Professional Practice (National Academy of Engineering, 2008; "Policy Statement 465," 2002).

In both the NAE Workshop and the aforementioned literature, we see tensions and/or communication gaps that could lead to polarization between engineering and social justice. This predicament raises an important question: how do we understand the possible origins of such communication divides? What frameworks might help us characterize these tensions and communication gaps? It could be argued that there is a simple misunderstanding of definition or vocabulary at work; however, we find such an explanation overly simplistic. Rather, we argue that these tensions and communication gaps may stem from an inability of each group to understand the complex frameworks undergirding each "side's" words and ideas. Since it is outside the scope of this paper to explore all possible frameworks, we instead focus on two macro-sociological frameworks, which accentuate contrasts in how people view societal organization. For all involved in the aforementioned communication divides, these two frameworks hold the potential to unveil the origins of conceptual and political tensions. They may also hold up to all groups a mirror of sorts, in which we might view how our own predominant conceptual frameworks on societal organization shape not only our thoughts about SJ but about those who seem to resist our conceptions of SJ.

The frameworks we engage in this paper are not the only ones that can help characterize tensions between engineering and SJ as fields of practice. For instance, one could also use the Cultural Cognition Thesis (e.g., Kahan, Jenkins-Smith, \& Braman, 2011) or the dominator and partnership models (e.g., Eisler \& Loye, 1990). Also, if one switches from viewing societal organization to taking

\footnotetext{
2 The problematic nature of the NAE Grand Challenges with respect to social justice was addressed by engineering educators Dean Nieusma, Xiaofeng Tang, Donna Riley, Amy Slaton, Joseph Herkert, and George Catalano in a session titled "Ethical Perspectives On The Grand Challenges Of Engineering" at the 2011 ASEE Conference in Vancouver, Canada.
} 
a broad philosophical viewpoint, one could investigate the viability of two philosophical frameworks: utilitarianism, which has socio-historical connections especially to U.S. engineering, and deontology, as it relates to social justice. However, we selected the two macro-sociological frameworks instead for three primary reasons:

1. The sociological frameworks do not focus on individual choices and consequences but on societal, collective choices, which maintains the focus on broader systemic issues. Unlike other theoretical frameworks, the two we chose attempt to characterize how people view societal organization writ large, which in turn yields insight into how societal-level planning is conceptualized and conducted.

2. Unlike the other frameworks, the sociological ones have a relatively long and established history, so possibilities exist to learn from a lengthy, rich debate.

3. Our initial theoretical examination of the connection between the sociological frameworks and engineering and social justice showed a significant degree of conceptual alignment between the first sociological framework and engineering and between the second framework and SJ. By contrast, no similarly robust conceptual alignments emerged in a brief exploration of the inverse-the first sociological framework with SJ and the second framework with engineering.

Before we explore links between engineering and SJ and the two frameworks, we should acknowledge that it would be reductive to suggest that all advocates of the engineering status quo or engineering for SJ perspectives completely inhabit one conceptual framework, or that some engineers do not see themselves holding multiple perspectives. Certainly, our intent is not to suggest such a false, simple binary. Also, our exploration is not intended to be comprehensive; rather, it is to examine the insights that emerge from a conceptual alignment of two frameworks and to consider what light is then shed on the origins of (in)commensurability between engineering and social justice. It is important to note that we use the term (in)commensurability (note parentheses) and not incommensurability. The former term denotes the possibility that engineering and SJ may be either-or some combination of both-commensurable and incommensurable. Also, we are not using this term in the sense used by Thomas Kuhn (1970, 1976), but in a broader, general sense, meaning that engineering and SJ may be reconcilable and/or irreconcilable as respective fields of practice.

\section{StRuCtURAL FUnCtionaliSM AND SOCIAL CONFLICT: Is SOCIETy AN ORganism OR IS SOCIAL Conflict a CATAlyst for Change?}

Is society more akin to an organism and complex system, or is social conflict a catalyst for change? This question elucidates crucial contrasts between the two frameworks we consider here-the structural-functionalist (SF) framework and the social-conflict (SC) framework. ${ }^{3}$ Historically, SF proponents have seen society as analogous to a body or organism, whereas SC advocates see inequities in social organization as conducive to social conflict, which in turn becomes a catalyst for social change. Hence, the core questions that each group asks-and their core principles-differ significantly. We argue that understanding the principles of these two frameworks can deepen our

\footnotetext{
${ }^{3}$ We are well aware that the contrast between these two frameworks has informed debates in sociology and social theory for a long time. Distinctions between functionalist and social-conflict theorists form the content of many graduate courses in these disciplines. Our goal here is not to enter those debates but to highlight the distinctions insofar as they illuminate (in)commensurabilities between engineering and SJ.
} 
understanding of the tensions and communication gaps between those who defend a status-quo form of engineering and those who embrace a vision of engineering more in line with SJ values. Since relatively few readers are likely to be sociologists, in this section, we introduce the SF and SC theoretical positions before applying them to our discussion of engineering and social justice.

\section{Society as an Organism}

Our discussion of SF and SC draws heavily from sociologists who provide broad introductory overviews of these concepts (Macionis, 2009; Abrahamson, 2001) and to a lesser degree from more detailed explanations (Wallace \& Wolf, 2006). Structural functionalism-which we see as having more parallels with certain engineering worldviews than social justice worldviews-can be understood by examining its core questions (adapted from Macionis, 2009):

- How is society held together?

- What are society's major components? Which components are more important for society's functioning? Which ones are less important? Who deserves to be in charge of the critical vs. non-critical components? How are these components connected?

- What does each component do to help society work? What kinds of social behaviors might be detrimental to efficient societal functioning?

Such questions emanate from the issues noted in Table 1.

\begin{tabular}{|ll|}
\hline Issue & Structural-Functionalist Framework \\
\hline $\begin{array}{l}\text { 1. View of Social } \\
\text { Stratification }\end{array}$ & $\begin{array}{l}\text { Stratification is universal, natural and socially beneficial. Division of labor is } \\
\text { justified between those in charge of critical vs. non-critical components and } \\
\text { functions. }\end{array}$ \\
\hline $\begin{array}{l}\text { 2. Function of } \\
\text { Stratification }\end{array}$ & $\begin{array}{l}\text { Rewards of wealth, power and status match functional importance. Experts in } \\
\text { charge of critical components and functions receive greater social rewards. }\end{array}$ \\
\hline $\begin{array}{l}\text { 3. Stratification and } \\
\text { Social Cohesion }\end{array}$ & $\begin{array}{l}\text { Stratification promotes cohesion by rewarding and incentivizing talented people } \\
\text { to perform more important work while justifying why those in less important } \\
\text { jobs need to keep their place. }\end{array}$ \\
\hline $\begin{array}{l}\text { 4. Overarching } \\
\text { Image of Society }\end{array}$ & $\begin{array}{l}\text { Society is an integrated, interdependent system that promotes function, order } \\
\text { and stability and must promote its own continuity. }\end{array}$ \\
\hline
\end{tabular}

Table 1: Characteristics of the Structural-Functionalist Framework Related to Social Stratification (adapted from Macionis, 2009).

To understand this perspective, it is necessary to look briefly at the first three dimensions in Table 1. First, for the structural functionalist, social stratification is universal, natural and benefits society (Davis \& Moore, 1945). Determined mainly by function, social stratification refers to how society ranks people into various hierarchies such as groupings according to wealth, power and/or prestige (Macionis, 2009). The second dimension explains the first; structural functionalists reason that social stratification exists to ensure that different levels of talent are rewarded according to the functional importance of a position (e.g., a brain surgeon receives more rewards than a nurse and both are expected to understand and respect their social position). They contend that this system promotes incentives for productivity and efficiency since increased rewards (income, social prestige, power, access to resources, etc.) will encourage people to work harder and more efficiently. Overall, SF theorists hold that social stratification exists to reward and incentivize talented people to perform more socially important work (Macionis, 2009). Those lower in the hierarchy can aspire to move to higher levels, not through political activism or revolt, but through hard work and preparation in more complex functions. 
The first three characteristics in Table 1 conceptually cohere to the overarching view of society (Macionis, 2009). Structural functionalists conceptualize society as a complex system with interdependent components. Analogies to such a system include a human body, other biological organisms or a machine with integral components (e.g., the circulatory, respiratory, or parts, feedback loops, etc.). These components work together to promote function, order and stability and ensure the continuity or perpetuity of the system. Thus, structural functionalists see society as a system of harmoniously interrelated parts that is relatively stable, wherein each part works to keep society functional and orderly (Wallace \& Wolf, 2006). They believe that members of society generally agree on right and wrong, which also promotes function and order. By implication, for structural functionalists the existence of social injustice is an unfortunate necessity to keep the entire system functional and stable. "Social inequality is thus an unconsciously evolved device by which societies insure that the most important positions are conscientiously filled by the most qualified persons" (Davis \& Moore, 1945, p. 243). It follows, then, that the core questions noted above relate to social cohesion, order and interdependent functionality.

Many engineers find this framework very appealing for a number of reasons. First, it provides them with a view of society that they can relate and contribute to, especially if society is viewed as a machine or system that operates under predictable physical laws. Engineers are familiar with complex, interdependent systems. Second, it positions engineers in charge of key components and systems that, for example, regulate the flow of key goods and services in society, hence rewarding them with relatively high salaries and status as the group in charge of planning and/or maximizing the efficiency of such flows. And third, it justifies the distinctions (in salary, power, status, etc.) between engineers and, say, technologists, technicians and mechanics. ${ }^{4}$

\section{Social Conflict as a Catalyst for Social Change}

In contrast, social-conflict theorists ask quite different core questions (adapted from Macionis, 2009):

- How does society divide a population? How do some groups establish and maintain power over others?

- How do advantaged people protect their privileges? Why might disadvantaged people accept those privileges?

- How do disadvantaged people challenge social order seeking change?

Such questions emanate from the issues noted in Table 2.

\footnotetext{
4 This association of engineers with functionalist frameworks of society, often coined as technocracy, has a long history in different countries. For a general account in the US, see (Akin, 1977). For an account in the USSR, see (Bailes, 1978). For an account in Chile, see (Silva, 2008)
} 


\begin{tabular}{|ll|}
\hline Issue & Social-Conflict Framework \\
\hline $\begin{array}{l}\text { 1. View of Social } \\
\text { Stratification }\end{array}$ & $\begin{array}{l}\text { Stratification is not inherently "natural"; it often results from one social group } \\
\text { establishing control over another. Hence it benefits some and disadvantages others. }\end{array}$ \\
\hline $\begin{array}{l}\text { 2. Function of } \\
\text { Stratification }\end{array}$ & To maintain the power or domination of one group over another. \\
\hline $\begin{array}{l}\text { 3. Stratification and } \\
\text { Social Cohesion }\end{array}$ & $\begin{array}{l}\text { Stratification promotes social conflict due to stark differences in wealth, prestige } \\
\text { and power. }\end{array}$ \\
\hline $\begin{array}{l}\text { 4. Overarching } \\
\text { Image of Society }\end{array}$ & $\begin{array}{l}\text { Society is a system of social inequalities that benefit some and harm others; conflict } \\
\text { leads to social change. }\end{array}$ \\
\hline
\end{tabular}

Table 2: Characteristics of the Social-Conflict Framework Related to Social Stratification (adapted from Macionis, 2009).

To understand this framework-which we see as having more parallels to SJ-oriented worldviews than to many traditional engineering worldviews-it is necessary to look briefly at the first three dimensions in Table 2. In response to functionalists, SC theorists hold that while stratification may be universal, its most salient aspect is that it benefits some and disadvantages others (Tumin, 1953). Further, and in contrast to functionalists, SC theorists say that social stratification has limited functionality for multiple reasons. For instance, rewards do not always reflect functional importance (e.g., former U.S. talk-show host Oprah Winfrey earns more in a day that Barack Obama does as U.S. President in a year) (Macionis, 2009). Also, other factors shape what constitutes societal importance; for instance, physicians' salaries are partly a product of medical schools that intentionally limit the supply of graduates (Tumin, 1953). Further, conflict theorists note that social stratification can have an effect opposite to what functionalists claim, actually preventing the development of individual talent; for instance, the children of the wealthy often have educational and other advantages and opportunities that will not be available to even highly talented children from poor families (Macionis, 2009). Such privilege could maintain social hierarchies and prevent social mobility (Wallace \& Wolf, 2006). Additionally, social stratification, if accompanied by a relatively materialistic culture, could also devalue highly functional social actions that may have no direct material value (e.g., parenting, playing music, being a good friend, etc.). In contrast to functionalists, conflict theorists say that social stratification, rather than merely rewarding and incentivizing talented people, often leads to social conflict due to stark differences in wealth, prestige and power (Macionis, 2009).

The first three characteristics in Table 2 conceptually cohere to the overarching view of society (Macionis, 2009). Conflict theorists view society not as an interdependent, efficiently functioning organism but as a system of social inequalities (based on class, gender, race, etc.), which benefit some and harm others. So the existence of social inequality and social injustice causes conflict that leads to social change. Thus, it is not surprising that the core questions of the social-conflict framework relate to inequality divides, privilege and social change.

Many engineers find this framework problematic for a number of reasons. ${ }^{5}$ First, it does not provide them with a view of society that they can relate and contribute to, especially when social change is the result of conflict instead of technological innovation in systems that promote social functioning. Second, it positions engineers, by virtue of their power or relation to capital, as antagonists to other groups with less power (e.g., machine workers). And third, it potentially

\footnotetext{
${ }^{5}$ We are well aware that there are historical and contemporary exemptions to this generalization. For example, Peter Palchinsky, Russian engineer during the rule of Lenin and Stalin, constantly questioned the oppression of workers under both capitalism and socialism and advocated for social change (Graham, 1993). Also see (Wisnioski, 2003).
} 
undermines and critically questions the distinctions (in salary, power, status, etc.) between engineers and, say, technologists, technicians and mechanics. ${ }^{6}$

\section{An Overview of Conceptual Alignments between Engineering and Structural FunCtIONALISM AND BETWEen SOCIAL JUSTICE AND SOCIAL CONFLICT}

So how do these two frameworks relate to engineering and SJ? Some engineers objecting to SJ at the 2008 NAE Workshop placed a great deal of emphasis on maintaining functional social order and not appearing to take a "political" stance. Certainly, advocating for social cohesion, order, efficiency and interdependent functionality may seem neutral, in part because these constitute a dominant perspective or commonplace assumption about societal organization. Who would object to such worthy ends, especially if engineering were to bring them about? However, by taking such positions, some engineers maintain the illusion of political neutrality, all the while acting in political ways. As Riley has noted, social inaction is also an action, often in support of the status quo, and all engineering has political dimensions given "the ways in which engineering is embedded in political processes" (Riley, 2008, p. vi). Yet advocating for social cohesion, order, efficiency and interdependent functionality still seems objective or neutral. Riley points out that "to claim that engineering is (or should be) objective [or neutral] is to presume a certain political attitude. Those who try to pretend that engineering is somehow objective and try to remove it from the political arena are themselves acting in a political way" (Riley, 2008, p. vi).

Also at the NAE Workshop, conceptual connections emerged between some engineers and engineering educators advocating for SJ and the social conflict approach, especially as such individuals frequently invoked discourses regarding social privilege, power and prestige. These initial connections between engineering and the SF framework and between social justice and the SC framework led us to conduct a more detailed theoretical exploration of overlaps and alignments. It should be reiterated that at the NAE Workshop some engineers predominantly advocated for the status quo while other engineers and engineering educators advocated moving toward an SJ-centric engineering education and engineering profession; our purpose here is to try to better understand the underpinnings of such positions.

\section{INTERSECTIONS BETWEEN ENGINEERING AND STRUCTURAL FUNCTIONALISM}

In Table 3, we have summarized the results of an analysis of conceptual alignments between the structural-functionalist framework and engineering.

\footnotetext{
${ }^{6}$ For the most comprehensive account of engineers' adherence to the system and the corporations that built them, see Wisnioski, Matt. "From system builders to servants of the system." Unpublished manuscript; for information, contact mwisnios@vt.edu.
} 


\begin{tabular}{|c|c|c|}
\hline & Structural-Functionalist Framework & U.S. Engineering \\
\hline \multirow{4}{*}{$\begin{array}{l}\text { Norms, Values, } \\
\text { Beliefs and } \\
\text { Assumptions }{ }^{7}\end{array}$} & $\begin{array}{l}\text { 1. Value expert outsider knowledge and } \\
\text { specialization in different fields; thus, the norm } \\
\text { is that subjective knowledge is devalued. }\end{array}$ & $\begin{array}{l}\text { Value expertise, objectivity, } \\
\text { scientific detachment/ disinterest, } \\
\text { positivism. }\end{array}$ \\
\hline & $\begin{array}{l}\text { 2. Value traditional views and roles of women in } \\
\text { society; encourage marginalized groups to } \\
\text { keep their place. }\end{array}$ & $\begin{array}{l}\text { A culture marked by sexism has at } \\
\text { times marginalized women in a } \\
\text { traditionally male-dominated field. }\end{array}$ \\
\hline & $\begin{array}{l}\text { 3. Assume social integration-that all parts fit } \\
\text { together and work toward social function; thus } \\
\text { instances of conflict are seen as aberrations, } \\
\text { especially if they disrupt the efficient flow of } \\
\text { goods and services between functional parts. }\end{array}$ & $\begin{array}{l}\text { As a corollary, assume that } \\
\text { technical order and function are } \\
\text { generally inherently positive } \\
\text { because these maintain efficient } \\
\text { flows among functional parts. }\end{array}$ \\
\hline & $\begin{array}{l}\text { 4. Belief that one should not be as engaged in } \\
\text { questioning what social functions we have } \\
\text { inherited but in explaining how they function to } \\
\text { promote social order and stability. }\end{array}$ & $\begin{array}{l}\text { Belief that value comes from } \\
\text { functionality ("if it works, it's } \\
\text { good"). }\end{array}$ \\
\hline
\end{tabular}

Table 3: Conceptual Connections between the Structural-Functionalist Framework and Norms, Values, Beliefs and Assumptions in the Engineering Profession and Engineering Education.

Each of the four areas of alignment is discussed below. Since engineering cultures vary between countries, we selected U.S. engineering largely because we are more familiar with this culture.

1) Structural functionalists value the inferences of experts over those of non-experts, because experts can supposedly research without bias, and have the necessary distance and detachment that non-experts lack (Abrahamson, 2001). This value stemmed from the concern that non-experts would not be able to effectively categorize and fully comprehend all the information they know. In that sense, subjective knowledge is devalued, and valid knowledge rests within the domain of experts.

Similarly, engineers tend to share structural-functionalist valuing of expertise, objectivity and scientific detachment/disinterest. For instance, research on engineers' styles of collaborative suggests a potential focus on isolated divisions of labor, with little actual collective decision-making, cooperation or significantly-interactive learning from others. However, this same research also found a mitigating factor, that discipline was less influential on collaborative style than a given individual's level of interest in the purpose of a research project (Borrego, 2006).

The notions of objectivity and expertise also relate to engineers' positivistic outlook. For instance, multiple authors note how positivism (especially the notion that science is "objective" and a matter of uncovering what is really there) manifests itself in multiple ways (Sarewitz, 1996). Such a worldview can result in communicative actions that destabilize effective collaborative relationships; such actions often seem immune from critique when traveling under the cover of expertise and objectivity. For instance, in public meetings, some contend that it is not uncommon that an "engineer takes on a position of arrogance, assumes she/he 'knows the real story' and that her/his job is to get the public to accept the version of the truth she/he has been given or has come to understand" (Riley, 2008, p. 115).

By contrast, several scholars advocate a more inquisitive, open approach about what people know, what knowledges count, and who holds expertise (Nieusma, 2011; Endres, 2010; Wynne, 1996).

${ }^{7} \mathrm{~A}$ framework consisting of beliefs, assumptions, values and norms is drawn loosely from the work of (Schein, 2010). 
Such an approach requires effective listening. Yet research suggests that for all their technical knowledge and prowess, engineers, lamentably, do not appear either well equipped with openness toward and awareness of non-engineering perspectives or trained in effective listening (Leydens \& Lucena, 2009). As one engineer has admitted, engineers "perhaps do not have sufficient depth and breadth of perspective for situating their work within the larger whole, or critically evaluating it from non-engineering perspectives" (Newberry, 2007, p. 112). That engineer posits that the "lack of [a broader] perspective by engineers is a product of an engineering educational system that has systematically undervalued non-technical learning" (Newberry, 2007, p. 112). Ethnographic research has also shown that students digest this university culture value from their engineering professors and learn to devalue non-technical or less technical learning (Downey \& Lucena, 2003; Godfrey \& Parker, 2010). Thus, the devaluing of the non-technical, including subjective knowledge, can be perpetuated across generations, passed down from instructor to student in a continuous cycle. Within the (often spurious) technical-nontechnical binary, SJ is generally placed squarely in the nontechnical domain, making it less valued and seemingly more subjective than technical work among engineers who hold to that binary.

2) Functionalists were critiqued for their problematic views of women and women's social roles (e.g., Abrahamson, 2001). Such problematic views catalyzed research into new theoretical frameworks to account for gender and gender-related labor differences (Johnson, 1989). According to SF's social organism/mechanism model, assigned roles to social groups are beneficial to society as long as these roles contribute to the efficient functioning of systems and components. Women fulfill key functions in society (giving birth, raising children, maintaining the household). Their social function thus conceived, they should be kept in that role for functional social efficiency. Although this view may seem archaic by modern standards, such thinking was still blatant in official publications in the 1950s:

In 1955, Eric Walker, Penn State University's engineering dean, wrote a column saying, 'Women are NOT For Engineering.' Walker declared that most women did not have the 'basic capabilities' needed for engineering. He concluded that teaching them didn't make sense; since '[t]he most evident ambition of many women is to get married and raise a family ... few companies are willing to risk $\$ 10,000$ on a beautiful blonde engineer, no matter how good she may be at math'. (Bix, 2004, p. 33)

Such sexism later persisted in often less blatant but nonetheless marginalizing forms. Both engineering education and engineering practice have been critiqued for being both male dominated and for creating barriers to women. Research suggests that predominating masculinist values can marginalize women or trivialize their potential intellectual contributions in science, math and engineering (Tonso, 1996a; Tonso, 1996b; Seymour \& Hewitt, 1997). Hence, we suggest that engineers' alignment with SF principles might help us understand the persistent culture of sexism within engineering.

3) Structural functionalists assume as natural a state of social integration-that all social parts fit together and work toward social order and function. Thus, they view change with apprehension and downplay conflict, opposition and power issues as aberrational (Abrahamson, 2001). For instance, some authors suggest that an airport serves as an effective analogy for the functionalist approach to interrelations of parts; if one component in the system breaks down, it can affect all others, including weather, radar controls, passenger volume, ticketing and reservation personnel, maintenance crews, pilots, flight attendants and more (Wallace \& Wolf, 2006). As a corollary, engineers tend to assume that technical order and function are generally natural and inherently 
positive. Such a perspective avoids questions of central importance to SC theorists, such as for what ends, for whose benefit and by what means social integration is achieved. By contrast, in those instances when engineers do recognize the culturally and historically situated nature of technologies, they tend to see any resulting social conflict and opposition as outside the domain and purview of engineers. For instance, one engineer posits a theory of why the idea of engineers working for the benefit of humanity may be inherently problematic: "We [engineers] have no crystal ball, and in most cases we lack anything even approaching a thorough and insightful assessment of a technology's far-reaching impact. Thus we rely mainly on first order appraisals, and we oil squeaky wheels" (Newberry, 2007, p. 111).

4) Some functionalists believe that one should not be engaged in questioning what social functions we have inherited but in explaining how they function to promote social order and stability (Abrahamson, 2001). As noted above, the body metaphor implies a kind of beautiful perfection-as highly complex systems (circulatory, respiratory, etc.) act harmoniously and interdependently to facilitate bodily order and function. Value lies in researching how the body functions so that one can explain-not question-this marvel. Analogously, each generation inherits social structures from the previous generation that are not of the current generation's making, so the task for functionalists involves studying social structures to understand them, including their origins and how they foster order and function. The underlying assumption is that it is "normal for the parts of a society to fit together and to function to maintain solidarity" (Abrahamson, 2001, p.2; see also Wallace \& Wolf, 2006). To reiterate, from this perspective, conflict and opposition are viewed as aberrations.

Similarly, engineers believe that the value of technology comes largely from functionality-that is, if it works, it is good. "After all," Newberry writes, "engineers are essentially doers-practical and action oriented, masters of constrained problem solving... In short, engineers take engineering de facto to be beneficial, if not in a utopian sense, then at least in a utilitarian one" $(2007, \mathrm{p}$. 112). So one task of an engineer is to design or create (and sometimes explain the function of) complex technical systems, yet there is often a corresponding unwillingness to question those same systems, whether that involves questioning society at large or corporate leaders. Such an instrumentalist belief is one that assumes that "because technology is [a] technical matter, it is also value free and neutral.... It is simply a tool" (Kaplan, 2004, quoted in Newberry, p. 109). In explaining why engineers rarely rock the corporate boat and tend to have values aligned with corporate cultures, Newberry posits one idea and borrows another.

Perhaps ... engineers, with their techno-rationality, with their pragmatic optimism, and with their affinity for concrete problem-solving, are singularly well-suited to embrace the organizational, managerial, economic, and technological milieu of corporations. Or, as Noble (1977) has suggested, perhaps industry has forcefully shaped the mechanisms for engineering education and professional socialization in order to produce a 'domesticated breed of engineer'. (Newberry, 2007, p. 113)

Certainly other explanations may also be posited, but regardless of the reasons for engineers' tendency to design rather than question technology, others counter by encouraging engineers to ask difficult questions. For instance, Riley suggests we ask, "for whom is engineering done, who wins and who loses by the actions of engineers, what work is considered engineering, and what values underlie the drawing of these professional boundaries" (2008, p. 110; see also Baillie, 2006). These are quintessential social-conflict questions applied to engineering. Yet often, as doers and masters of problem solving, engineers are interested in discovering, maintaining and enhancing functionality and maximizing efficiency, not questioning it or its social ramifications. The trouble 
with not questioning and only explaining functionality is that a host of other issues impinge on (and are impinged upon by) engineering work, such as the question of power. Engineering expertise could be co-opted by powerful forces, and historically, it has been. For instance, in the first decades of the $20^{\text {th }}$ century,

[a]s America lost interest in reform, engineers either rejected the idea of social responsibility or gave it a conservative interpretation. The close alliance between engineering and business that developed in the 1920s brought many material benefits. But the profession lost much of its precious independence. The studies of waste and the twelve-hour day demonstrated the sort of contributions an autonomous engineering profession might have made to national life.... There can be little doubt that engineers derived substantial benefits from their alliance with business. But there was a danger that in gaining worldly things the engineering profession might have lost its own soul. (Layton, 1971, p. 201, p. 218)

It merits noting that for structural functionalists, their work led to explanations-not questioningof social function while for engineers, their work frequently involves creating, modeling or designing-not questioning-technical function. This comparison may have some weakness, but it does raise a key question: Does how one views society shape how one views technology-and vice versa? Functionalists invoked and extended Adam Smith's concept of the invisible hand (Abrahamson, 2001), whereby individual attributes such as greed did not taint the larger economic system, which was believed to be self-regulating and ultimately work to benefit all. In fact, Smith saw self-interest as an essential ingredient in economic functionality.

Given that metaphor, it is intriguing how one engineer describes engineers' general view of technology: “...despite the fact that corporations develop their technological products for profitdriven, rather than altruistic, ends, engineers are likely to have a vague perception of a Smithian invisible hand guiding the process in a beneficial direction, one which, in aggregate, represents progress and improvement" (Newberry, 2007, p. 113).

\section{INTERSECTIONS BETWEEN SOCIAL CONFLICT AND SOCIAL JUSTICE}

In Table 4, we have summarized key conceptual alignments between the SC framework and SJ scholarship.

\begin{tabular}{|l|ll|}
\hline & Social-Conflict Framework & U.S. Social Justice Advocates \\
\hline \multirow{4}{*}{$\begin{array}{l}\text { Norms, Values, } \\
\text { Beliefs and }\end{array}$} & $\begin{array}{l}\text { 1.Value social conflict for assisting in fostering } \\
\text { social change; social conflict is integral to the } \\
\text { process of social progress. }\end{array}$ & $\begin{array}{l}\text { Generally, SJ assumes that social } \\
\text { conflict can foster social change. }\end{array}$ \\
\cline { 2 - 3 } & $\begin{array}{l}\text { 2.Value the important roles of power and } \\
\text { inequality in social conflicts and value people } \\
\text { as agents in social-change processes. }\end{array}$ & $\begin{array}{l}\text { Hold both values noted at left, } \\
\text { asking, "Who benefits and who } \\
\text { pays?" as well as "Who is included?" }\end{array}$ \\
\cline { 2 - 4 } & $\begin{array}{l}\text { 3. Assume that SC is based on competing values } \\
\text { and beliefs that can lead to new normative } \\
\text { positions, consensuses. }\end{array}$ & $\begin{array}{l}\text { Assume cognitive dissonance and } \\
\text { other frameworks promote SJ. }\end{array}$ \\
\hline
\end{tabular}

Table 4: Conceptual Connections between the Social-Conflict Framework and SJ Scholarship

Each of the points in Table 4 merits further discussion. Since SJ advocates are shaped by their surrounding culture, SJ norms, values, beliefs and assumptions cannot be assumed to be universal; our focus here is on U.S. SJ, the context we know best, yet even within that focus, we make some admittedly simplistic generalizations. Also, here we are not summarizing the views of U.S. SJ 
advocates as much as we are noting some of the scholars that have informed U.S. SJ, such as the German-born Canadian Ursula Franklin and British scholar Caroline Baillie.

1) Advocates of both SC and SJ value social conflict for its potential in catalyzing social change. While structural functionalists viewed social conflict as an anomaly or aberration to otherwise orderly and functional society, SC theory sees conflict as integral to the process of social progress. ${ }^{8}$

Generally, SJ advocates also note that social conflict can foster and has historically fostered social change. For instance, a review of the history of social change in the U.S. generally reveals that social conflict played a principle role in events precipitating abolition, suffrage, desegregation, civil rights, disability rights and other SJ movements (Myers-Lipton, 2006). Indeed, many in SJ would extend the insights of Frederick Douglas on abolition movements to SJ movements in general: "If there is no struggle there is no progress.... Power concedes nothing without a demand. It never did and it never will” (1857). During the campaign for civil rights, Martin Luther King, Jr. echoed Douglas' notion in a letter from a Birmingham jail, when he noted that historically, "freedom is never voluntarily given by the oppressor; it must be demanded by the oppressed" (1963). Hence, considerable alignment occurs between SC theorists and SJ advocates that social conflict remains integral to the process of social progress.

2) Considerable conceptual alignment also occurs on the issue of power and inequity. Advocates of SC theory tend to accentuate the important roles played by domination, power and inequality in social conflicts, which structural functionalists downplayed. Also, SC theorists see people not just as reactors to but as agents in social change processes (Abrahamson, 2001). Thus, SC theorists' approach contrasts with SF theory, which largely avoided issues of power and inequality by viewing social benefits as a logical outcome of serving in different functions; suffering in such a view can be seen as an "aberration" that needs to be corrected by improving a function (e.g., homelessness can be ameliorated by issuing food vouchers to the homeless).

Similarly, regarding power and inequality, SJ advocates frequently examine questions of who benefits and who suffers, what individuals or groups are privileged or disenfranchised by legislation or social norms, rules or regulations and how enacted "justice" affects the social whole (Baillie, 2009; Catalano, 2009; Baillie \& Catalano, 2009; Capeheart \& Milovanovic, 2007; MyersLipton, 2006; Riley, 2008). In discussing the history of social justice, Capeheart and Milovanovic note that even conceptions of justice have long been top-down, inherited from privileged elites. Only recently (and more rarely) have bottom-up conceptions begun to surface (2007). Riley invokes such power issues when challenging fellow engineers to examine implicit biases in the profession, including "who benefits and loses from engineering ... who can and cannot do engineering ... [and] what counts and does not count as engineering" (Riley, 2008, p. vi). In multiple ways, SJ advocates address power and inequity issues, four of which seem predominant vis-à-vis technology: through examining sociotechnical consequences, commonsense sociotechnical assumptions, sociotechnical agents and stakeholders, and by using participatory approaches to consensus building.

Examining sociotechnical consequences - The important roles played by domination, power and inequality in social conflicts are accentuated by multiple SJ advocates and in case studies. For

\footnotetext{
${ }^{8}$ Note that SC theories differ from Marxism in several ways: whereas Marx placed primary emphasis on material origins of social conflict, for conflict theorists those origins can be normative or material; also, social conflicts vary in intensity and impact, and a recognition exists that not all conflicts necessarily lead to social changes or revolutions (see Abrahamson, 2001).
} 
instance, metallurgist and SJ promoter Franklin emphasizes critical explorations of both the benefits and harms of technology (1999). Franklin distinguishes between divisible and indivisible costs and benefits via an example of growing tomatoes and fighting pollution. A divisible cost would include the labor involved in planting, weeding and harvesting tomatoes with friends, and a divisible benefit would be the harvest shared among those friends. By contrast, if you somehow lower pollution levels, your collaborators clearly benefit, yet so do non-collaborators, through for instance cleaner air. So in this case the benefits are indivisible, shared by all. Publically financed technologies also take on an indivisible character, becoming part of the common good. However, as engineer and SJ advocate Baillie has noted, "[Franklin] describes how infrastructures that are publicly funded have become 'divisible benefits' to the private sector. Indivisible benefits, on the other hand, such as clean air and uncontaminated water are less and less safe guarded" (Baillie, 2009 , p. 25). For Franklin, commonsense values embedded in technology, especially regarding efficiency, a primary engineering value, have sometimes become public values. Although such commonsense values often remain unquestioned, Franklin encourages us to examine whether "efficient" technical solutions are also the most viable economically, socially and environmentally. Thus, we should consider who pays and who benefits when considering any technological "advancement" (Franklin, 1999).

Examining commonsense sociotechnical assumptions - Power and social inequity can become visible by examining such assumptions. For instance, Slaton considers commonsense assumptions and who pays and who benefits in a case study of 1960s Chicago (Slaton, 2010). At that time, city planners sought to revitalize Chicago, increase wealth opportunities across social classes and decrease poverty. Despite these admirable intentions, however, planners' assumptions about what engineering is and who can be an engineer fell along stratified racial and class lines. Specifically, they assumed individuals in the working class-primarily minorities-would be trained for lowerlevel technical work while engineering would be the purview of those who already had access to a university education-primarily whites. In a way, city planners were acting in the SF tradition by assigning different functions to different groups of people. Slaton's case study shows how such commonsense assumptions about race, class, careers, education and progress can thwart even the most well-intentioned SJ goals (2010).

Examining the roles of sociotechnical agents and stakeholders - SJ advocates pay attention to power and inequality issues by envisioning people not as mere reactors but as important agents in socialchange processes. Whereas SF theorists saw functional value in stratification, keeping existing social hierarchies intact, SC theorists recognize that people can be crucial agents in the meaningful reorganization of such social hierarchies. That focus on human agency accentuates stakeholder interactions, as Capeheart and Milovanovic point out: "social justice must include an understanding of the interactions within and between a multitude of peoples" $(2007, p$. 2). That multitude encompasses people from all social classes, races, genders and other backgrounds, who are conceived as important potential agents of social change.

Using participatory approaches to consensus building - As result of valuing multiple stakeholder perspectives, inclusive and participatory approaches to consensus building are part of SJ processes. Such approaches seek to destabilize traditional, top-down power relations. For instance, Baillie and colleagues chronicle their inclusive, participatory approach to a project called Waste for Life, conducted in Buenos Aires, Argentina (Baillie \& Catalano, 2009; Baillie, Feinblatt, Thamae, \& Berrington, 2010). Baillie and colleagues' work accentuates why needs assessment processes should include deliberate phases in which local needs, wants and knowledge are understood before technologies are planned or implemented (2009). Similar eschewing of hierarchical, nonparticipatory approaches occurs in the community-based work of several other scholars. For 
instance, Corburn's Street Science underscores the important role of local community experiences and knowledge in shaping environmental policies (Corburn, 2005). Further, Lucena, Schneider, and Leydens foreground why listening to and understanding local, cultural perspectives is crucial to the success of engineers in sustainable community development projects (Lucena, Schneider, \& Leydens, 2010).

3) Conflict theorists assume that social conflict is based on competing values and beliefs that can lead to new normative positions and consensuses. In that sense, whereas structural functionalists normalize harmonious social integration, SC theorists' broad sociological approach normalizes conflict as the means by which more equity-oriented social change occurs. By comparison, U.S. views on SJ also acknowledge how consensus can be wrought from dialogic interactions of contrasting values and beliefs.

SJ practitioners advocate fostering dialogic ideological exchanges. That is, if it is the clash of values and beliefs that stand to catalyze new social norms and consensuses, such clashes should be encouraged and discussed, not avoided or minimized as in the SF tradition. The work of Gorski (2009) and Goodman (2001) invites such dialogic exchange, albeit in different ways. Gorski uses cognitive dissonance as a strategy for teaching social justice. Popularized after Festinger's study of a doomsday cult's belief persistence (1962), the term cognitive dissonance refers to what occurs when our prior belief systems come into contact with new, contradictory information. Gorski structures cognitive-dissonance activities to accentuate disconnects between real and perceived knowledge to initiate discussions about how all people can be (un)consciously socialized to adopt ways of thinking that perpetuate injustice. For instance, one exercise involves a multiple-choice quiz in which students or workshop participants guess the sources of a series of quotations by famous individuals from U.S. and world history. Most quotations are surprising and unsettling since they counter commonsense assumptions: Thomas Jefferson's ideas on Christianity, Abraham Lincoln's White supremacy, Adam Smith's warnings about corporate capitalism, and more. Gorski considers the quiz and ensuing discussion "an exercise in what we think we know" (2009, p. 56). Participants in Gorski's classes and workshops are invited to reflect on which answers were most surprising and why, as well as on why these views have been omitted from mainstream histories and who benefits and who suffers from such omission. Participants also explore how their new knowledge might inform the way they respond to future encounters with new information (2009). Ideally, such disconnects engender reflection, discussion and new social consensuses that bring about greater social equity.

If new social consensus positions are to emerge via dialogue, they cannot be catalyzed by disenfranchised groups alone; privileged groups, who often hold more social power, must be actively engaged in the shaping of consensus. Goodman focuses on how privileged groups accept or resist SJ ideas (2001). Although marginalized groups also merit SJ dialogues and action, Goodman notes that since people from privileged groups tend to be unaware of their own privilege yet have the potential to act as powerful SJ change agents, it makes sense to focus on praxis for creating SJ allies among such groups. Goodman explains that individuals from privileged groups tend to lack awareness of systemic and institutionalized injustices, deny or avoid the existence of oppression and hold a sense of entitlement or internalized supremacy. To mitigate resistance to SJ education, Goodman proposes multiple strategies, such as challenging students and workshop participants to wrestle with how their own intellectual and social identity development can exacerbate or enable them to transcend such resistance. In conducting SJ education, Goodman assumes that social conflict is based on competing values and beliefs that can and do lead to new normative consensuses, and her work provides examples of transformations as a result of SJ education (2001). 
In closing, it should be noted that both SC theorists and SJ advocates see conflict as a means to an end but not an end in itself. They believe in working toward an ideal (though dynamic) balance between consensus and stability on the one hand and conflict and change on the other (Abrahamson, 2001). That is, society should not be embroiled in constant conflict and chaos to the point that social stability and the possibility of consensus are jeopardized. At the same time, society should not avoid conflict that can bring about new consensuses and forms of stability, as long as the new conflict-wrought consensus and stability augment the amount of equality, involve all perspectives and fairly distribute social rewards and burdens.

\section{Conclusion: Are Engineering AND SOCIAL JUStice (IN)COMmenSURABLE?}

The above discussion of alignments between engineering and SF as well as between SJ and SC have explored an important question: Given that they seem to exist in two different frames of reference, are engineering and SJ commensurable or incommensurable? Although our theoretical exploration cannot definitively answer that question, it does suggest some potential reasons for incommensurability between engineering and social justice. SJ advocates who hold an SC perspective may need a deeper understanding and appreciation that their assumptions and predispositions regarding societal organization are not shared by those holding SF perspectives. And such perspectives may be a source of resistance to SJ education. Specifically, resistance among some engineers to SJ ideas may be rooted in, among other things, a conscious or unconscious commitment to a SF perspective.

SJ advocates wanting to engage engineers in SJ dialogues should remain cognizant of, among other issues, the possibility that some engineers consider such SJ dialogues "political" or irrelevant given their views on societal organization, on the technical-nontechnical binary and on related topics. Understanding how some mainstream engineers' views might align with the SF perspective could help avoid dialogue ending in polarization and can facilitate more effective communication. Gaining the support of engineers for SJ may mean thoughtfully and ethically exploring-and certainly challenging-their prior conceptions and assumptions about societal organization. Discussions about societal organization are invariably charged since they touch on our core values and worldviews. Yet openly and explicitly acknowledging differences in the SF and SC frameworks could serve as a useful platform for SJ discussions with engineers since it could ground SJengineering contrasts in theoretical terms. At the same time, such a discussion risks becoming a mere intellectual abstraction, thus suspending relevant $\mathrm{SJ}$ transformations or action outcomes and dissipating the need to wrestle with troubling assumptions and beliefs. Hence, using an SF-SC framework should be one of many components of a SJ educational approach for discussions with mainstream engineers.

We are assuming here, as well, that dialogue between those operating within SF and SC frameworks is desirable; this assumption reveals our own predisposition toward facilitating communication across gaps or tensions. We realize that not everyone will see a need for such bridge building and, in fact, may find it counterproductive. SC adherents may see communication gaps with SF adherents as a necessary byproduct of radical action or social conflict, for example. Furthermore, we acknowledge that particular individuals may move between the SC and SF frameworks, depending on particular contexts and regarding particular issues: cognitively, spiritually and politically, humans are complex and resist simple categorization. As with all conceptual frameworks, this one should remain fluid and open to reinterpretation and adjustment. Future work should interrogate the frameworks we have laid out here, hopefully deepening, complicating and also expanding the parallels we have drawn between the SC and SF frameworks and engineering and social justice. 


\section{AREAS FOR FUTURE RESEARCH}

The limitations of this study invite future research in engineering and social justice. Since this is a theoretical paper, it calls for empirical verification. Empirical studies could explore conceptual links between engineering and SF and between social justice and SC. Such studies could also shed light on which perspectives best characterize tensions between engineering and SJ, such as SF and SC, the Cultural Cognition Thesis (e.g., Kahan et al., 2011) the dominator and partnership models (e.g., Eisler \& Loye, 1990), utilitarianism and deontology or other perspectives. We hope such empirical explorations occur in future SJ research.

We acknowledge the U.S. slant in this paper. Although the SF-SC debate took place in the U.S. beginning especially in the 1950s, that debate is not unique to U.S. sociology. For justifiable reasons, we also provide largely U.S. representations of engineering and SJ. Future research could investigate how the two sociological frameworks intersect with engineering and SJ in other cultural contexts. We expect that countries like Brazil, France and Mexico, where SF-SC frameworks have had significant influence in the development of the state, industry and education, would be prime sites for such research.

This paper explored conceptual alignments between engineering and SF as well as between SJ and SC. Although it was outside the scope of this paper, future research could also explore more systematically alignments between engineering and SC as well as between SJ and SF. Although fewer and less rich alignments resulted from our brief comparison, a more extensive examination of those alignments may yield unexpected and intriguing theoretical insights. In this paper, SF and SC have been presented in stark contrast. Future research may also want to take a less simplified view of SF and SC, exploring how nuanced conceptual alignments between those two seemingly oppositional frameworks might serve as signs that engineering and SJ could find more common ground.

For us, this paper has raised many important questions that could also serve as fodder for future inquiry. How does one put the insights from this theoretical exploration into practice? That is, how do engineering educators productively foster awareness of their own and their students' or colleagues' own framework(s) or worldviews? In this regard, what empirical research, if any, points to the most effective forms of ideological transformation for both SJ educators and mainstream engineers or engineering students? And perhaps most importantly, if engineering and SJ are actually incommensurable, what approaches might reconcile them? To this last question, we offer a few suggestions:

1) Continued or more assertive focus should be on inclusive excellence (e.g., Williams et al., 2005; Danowitz \& Tuitt, 2011). The persistent preponderance of gender and ethnic homogeneity in U.S. engineering in the $21^{\text {st }}$ century (particularly compared with law and medicine) renders useful and necessary attempts to broaden participation by historically marginalized groups via recruitment and retention efforts guided by principles of inclusive excellence.

2) Since sociologists have grappled with the SF-SC tension for over half a century, we stand to learn much from understanding more about how they have reconciled SF-SC tensions in research, theory and practice.

3) Conduct more investigations into the nature of barriers to and opportunities for commensurability, and into the theoretical and practical benefits and liabilities associated with commensurability between engineering and SJ. 
Further, this research underscores the importance of turning the ideological mirror. That is, while the SF framework may help us both understand and hold up a mirror to those holding some common engineering perspectives, it can also be useful to those of us who are engineering-for-SJ educators. What might we learn about our own ideological positions? How do we see our own views clashing and/or aligning in various degrees with SF and SC views? What implications does this reflexivity have for our own SJ praxis? What other frameworks also come into play as we reflect on our own ever-evolving ideological positions?

It may be tempting for SJ educators to adopt a self-righteous stance when encountering SF frameworks, but how might this research temper that and provide a more compassionate understanding of the origins of others' resistance to SJ education, of why we may disagree? And ultimately, how might understanding such origins lead to better communication about how engineering can be transformed so that SJ lives actively at its center? We look forward to fresh approaches to these questions from scholars committed to a more just future for engineering.

\section{ACKNOWLEDGEMENTS}

The authors would like to thank all those who gave input on an early draft of this paper at the $6^{\text {th }}$ Annual Engineering, Social Justice and Peace Conference, held in London in 2010. We are also grateful to the three anonymous reviewers for their helpful feedback, as well as the guidance of the editorial staff at IJESJP. Collectively, their input has made this a better paper. Finally, research on this paper was funded by a grant from the U.S. National Science Foundation, No. SES-0930213. Any opinions, findings, and conclusions or recommendations expressed in this material are those of the author(s) and do not necessarily reflect the views of the National Science Foundation.

\section{REFERENCES}

Abrahamson, M. (2001). Functional, conflict and neofunctional theories. Handbook of Social Theory. Sage. Retrieved from http://www.sage-ereference.com/hdbk soctheory/Article n12.html

Akin, W. (1977). Technocracy and the American dream: the technocrat movement, 1900-1941. Berkeley: University of California Press.

Bailes, K. (1978). Technology and society under Lenin and Stalin: origins of the Soviet technical intelligentsia, 1917-1941. Princeton N.J.: Princeton University Press.

Baillie, C. (2006). Engineers within a local and global society. San Rafael, CA: Morgan \& Claypool Publishers.

Baillie, C. (2009). Engineering and society: working towards social justice. Part I, Engineering and society. San Rafael, CA: Morgan \& Claypool Publishers.

Baillie, C., \& Catalano, G. (2009). Engineering and society working towards social justice. Part III, Engineering windows on society. San Rafael, CA: Morgan \& Claypool Publishers.

Baillie, C., Feinblatt, E., Thamae, T., \& Berrington, E. (2010). Needs and feasibility a guide for engineers in community projects: the case of Waste for Life. San Rafael, CA: Morgan \& Claypool Publishers.

Bix, A. (2004). From "Engineeresses" to "girl engineers" to "good engineers": A history of women's U.S. engineering education. NWSA Journal, 16(1), 27-49.

Borrego. (2006). Discipline-based views of collaboration in engineering education research partnerships. 36th ASEE/IEEE Frontiers in Education Conference (p. S1D-12-17). Presented at the Frontiers in Education Conference, San Diego, CA.

Capeheart, L., \& Milovanovic, D. (2007). Social justice: Theories, issues, and movements. New Brunswick, New Jersey, and London: Rutgers University Press.

Catalano, G. (2009). Engineering and society working towards social justice. San Rafael, CA: Morgan \& Claypool Publishers. 
Corburn, J. (2005). Street science: community knowledge and environmental health justice. Cambridge, MA: MIT Press.

Danowitz, M.A. \& Tuitt, F. (2011). Enacting inclusivity through engaged pedagogy: A higher education perspective. Equity \& Excellence in Education, 44(1): 40-56.

Davis, K., \& Moore, W. E. (1945). Some principles of stratification. American Sociological Review, 10(2), 242249.

Douglas, F. (1857). The significance of emancipation in the West Indies. Speech, Canandaigua, NY. Retrieved from http://www.lib.rochester.edu/index.cfm?PAGE=4398.

Downey, G. L., \& Lucena, J.C. (2003). When students resist: Ethnography of a senior design experience in engineering education. International Journal of Engineering Education, 19(1), 168-176.

Eisler, R., \& Loye, D. (1990). The partnership way: new tools for living \& learning. San Francisco: Harper.

Endres, D. (2010). Expanding notions of scientific argument: A case study of the use of scientific argument by American Indians. In L. Kahlor \& P. A. Stout (Eds.), Communicating science: New agendas in Communication (pp. 187-208). New York; London: Routledge.

Festinger, L. (1962). A theory of cognitive dissonance. Stanford CA: Stanford University Press.

Franklin, U. (1999). The real world of technology (Rev. ed.). Toronto, Ont.: Anansi.

Godfrey, E., \& Parker, L. (2010). Mapping the Cultural Landscape in Engineering Education. Journal of Engineering Education, 99(1), 5-22.

Goodman, D. (2001). Promoting diversity and social justice : educating people from privileged groups. Thousand Oaks CA: Sage Publications.

Gorski, P. (2009). Cognitive dissonance as a strategy in social justice teaching. Multicultural Education, 17(1), 54-57.

Graham, L. (1993). The ghost of the executed engineer: technology and the fall of the Soviet Union. Cambridge, MA: Harvard University Press.

Hollander, R. (2010). Upcoming engineering ethics workshops. National Academy of Engineering. Retrieved August 10, 2011, from http://www.nae.edu/15388.aspx.

Hollander, R., \& National Academy of Engineering; National Academies Press (U.S.). (2010). Engineering, social justice, and sustainable community development: summary of a workshop. Washington DC: National Academies Press.

Johnson, M. (1989). Feminism and the theories of Talcott Parsons. In R. A. Wallace (Ed.), Feminism and Sociological Theory (pp. 101-18). Newbury Park, CA: Sage.

Kahan, D., Jenkins-Smith, H., \& Braman, D. (2011). Cultural cognition of scientific consensus. Journal of Risk Research, 14(2), 147-174.

Kaplan, D. (2004). Readings in the philosophy of technology. Lanham Md.: Rowman \& Littlefield Publishers.

King, M. L. (1963). Letter from a Birmingham Jail. Retrieved from http://www.africa.upenn.edu/Articles_Gen/Letter_Birmingham.html

Kuhn, T. (1970). The structure of scientific revolutions. 2nd Ed. Chicago: Chicago University Press.

Kuhn, T. (1976). Theory-change as structure-change: Comments on the Sneed formalism. Erkenntnis 10(2): 179-199.

Layton, E. (1971). The revolt of the engineers: social responsibility and the American engineering profession. Cleveland: Press of Case Western Reserve University.

Leydens, J A. \& Lucena, J. C. (2009). Listening as a missing dimension in engineering education: Implications for sustainable community development efforts. IEEE Transactions on Professional Communication, Special Issue on Professional Communication in Humanitarian Environments, 52(4), 359-376.

Lucena, J.C., Schneider, J., \& Leydens, J.A. (2010). Engineering and sustainable community development. San Rafael, CA: Morgan and Claypool.

Macionis, J. (2009). Society: the basics (10th ed.). Upper Saddle River, NJ: Pearson/Prentice Hall. 
Myers-Lipton, S. J. (2006). Social solutions to poverty: America's struggle to build a just society. Boulder and London: Paradigm PublishersMyers-Lipton, S.J.

National Academy of Engineering. (2004). The engineer of 2020: visions of engineering in the new century. Washington DC: National Academies Press.

National Academy of Engineering. (2008). Grand challenges for engineering. Washington, D.C.: National Academies, National Academy of Engineering.

Newberry, B. (2007). Are engineers instrumentalists? Technology in Society, 29(1), 107.

Nieusma, D. (2011). Middle-out social change: Expert-led development interventions in Sri Lanka's energy sector. In G. Ottinger \& B. R. Cohen (Eds.), Technoscience and environmental justice: expert cultures in a grassroots movement, Urban and industrial environments. Cambridge, MA: MIT Press.

Noble, D. (1977). America by design: science, technology, and the rise of corporate capitalism. New York: Knopf.

Policy Statement 465: Why We Must Raise the Bar - ASCE Task Committee on the Academic Prerequisites for Professional Practice (2002). Civil engineering, 72(4), 60-65, 94-95.

Riley, D. (2008). Engineering and social justice. San Rafael, CA: Morgan \& Claypool.

Sarewitz, D. (1996). Frontiers of illusion: science, technology, and the politics of progress. Philadelphia: Temple University Press.

Schein, E. (1985). Organizational culture and leadership (1st ed.). San Francisco: Jossey-Bass Publishers.

Schein, E. (2010). Organizational culture and leadership (4th ed.). San Francisco: Jossey-Bass.

Seymour, E., \& Hewitt, N. M. (1997). Talking about leaving: why undergraduates leave the sciences. Boulder, CO: Westview Press.

Silva, P. (2008). In the name of reason: Technocrats and politics in Chile. University Park, PA: Penn State University Press.

Slaton, A. (2010). Ambiguous reform: Technical workforce planning and ideologies of class and race in 1960s Chicago. Engineering Studies, 2(1), 5-28.

Tonso, K. (1996a). The impact of cultural norms on women. Journal of Engineering Education, 85(3), 217-25.

Tonso, K. (1996b). Student learning and gender. Journal of Engineering Education, 85(2), 143-50.

Tumin, M. (1953). Some Principles of Stratification: A Critical Analysis. American Sociological Review, 18(4), 387-394.

Wallace, R., \& Wolf, A. (2006). Contemporary sociological theory: expanding the classical tradition (6th ed.). Upper Saddle River, NJ: Prentice Hall.

Williams, D.A., Berger, J.B., \& McClendon, S.A. (2005). Toward a model of inclusive excellence and change in postsecondary institutions. Washington, DC: Association American Colleges and Universities.

Wisnioski, M. (2003). Inside "the system": engineers, scientists, and the boundaries of social protest in the long 1960s. History and Technology, 19(4), 313-333.

Wynne, B. (1996). May the sheep safely graze? A reflexive view of the expert-lay knowledge divide. In S. Lash, B. Szerszynski, \& B. Wynne (Eds.), Risk, environment and modernity: Towards a new ecology (pp. 44-83). New York: Sage. 